\title{
Pathological findings in a case of hypothyroidism with ataxia
}

\author{
R. O. BARNARD, M. J. CAMPBELL, AND W. I. MCDONALD \\ From The National Hospitals for Nervous Diseases, Queen Square, and Maida Vale, London
}

SUMMARY A case of hypothyroidism with ataxia is described. At necropsy there were degenerative changes in the cerebellum, particularly in the anterosuperior portion of the vermis, together with atrophy of ventral portion of the pons, transverse pontine fibres, and middle and superior peduncles. The relationship between ataxia and pathological findings in myxoedema is discussed.

A cerebellar syndrome as a complication of myxoedema or hypothyroidism was described by Swedish workers in the early part of this century (Söderbergh, $1910,1911,1912)$, but then largely ignored until the report of Jellinek and Kelly in 1960. Since then there have been several papers concerned with the clinical aspects of this syndrome (Nickel and Frame, 1958; Nickel, Frame, Bebin, Tourtellotte, Parker, and Hughes, 1961; Cremer, Goldstein, and Paris, 1969). Two cases with necropsy have been reported (Uyematsu, 1920; Price and Netsky, 1966) but neither is entirely satisfactory. Severe atheroma complicated both, and Price and Netsky's patient was a chronic alcoholic of long standing.

We report here the neuropathological findings in a case of cerebellar dysfunction occurring in a woman with severe hypothyroidism who died suddenly from hypertensive cerebral haemorrhage four weeks after commencing thyroid replacement therapy.

\section{CASE REPORT}

W.A. (M.V.H. No. 61947), a woman aged 57, was referred in January 1967 because of progressive unsteadiness of gait for one to two years and occipital headaches for one year. Five years earlier she first noticed increasing drowsiness and slowness of thought. For two to three years she had become increasingly forgetful and had been forced to resort to a shopping list. Her gait gradually became unsteady during the two years before admission and during the last few months this became more severe and she fell several times. Her handwriting had deteriorated so much that her bank manager had requested a new specimen signature, but she herself had not noticed that her hands were clumsy. Over the same two year period her face had become puffy, her skin dry, her hair dry and brittle and her voice deep and husky; she had steadily gained weight and her bowels were costive. She had become intolerant of cold weather and frequently tended to sit huddled in front of her fire, readily falling asleep. For about a year she had suffered from occipital headaches which had become increasingly severe. The headaches were sometimes accompanied by nausea. She was short of breath on exertion, but there was no history of pain in the chest. She had not suffered any weakness or sensory disturbance in the limbs, and denied deafness. The menopause had occurred at the age of 50 years.

In the past she had had a left-sided mastoidectomy 10 years previously and her first child (now 21 years of age) had been delivered by Caesarian section. Her father had died from coronary thrombosis and her mother from the complications of diabetes mellitus. One sister had died from kidney disease at the age of 13 and one brother from coronary thrombosis at 58 years. One sister and one brother were alive and well. Her own four children were alive and well. She was a non-smoker and rarely took alcohol.

On examination she had a myxoedematous face and deep husky voice. The skin was dry and scaly. The head hair and eyebrows were thinned and the body hair markedly so; the hair itself was brittle. There was no goitre and no signs of neoplasia. The pulse rate was 80 per minute and in sinus rhythm; blood pressure was $190 / 135 \mathrm{~mm} \mathrm{Hg}$. There was clinical evidence of left ventricular hypertrophy. There was no sign of cardiac failure.

Although correctly orientated, she thought, spoke and moved slowly, and she had difficulty in placing events in time. Psychometry (Mr. J. Smith) showed that she was of average premorbid intelligence. A fair degree of impairment was found in all tests, sensitive to poor attention and distractability. This led to an initial impression of a far greater decline in intellectual function than was established on formal testing. The visual acuity was normal and the visual fields full to confrontation. The fundal arterioles were narrowed. Pupils were equal in size and reacted normally to light and on convergence. Ocular 
movements were full. There was no consistent nystagmus. There was no facial weakness or sensory loss. There was a slurring dysarthria. Tone and power in the limbs were normal. There was exaggerated rebound after depression of the outstretched arms against resistance. Voluntary movements were slow. There was some clumsiness of rapidly alternating pronation and supination in the upper limbs, but no intention tremor. There was moderate ataxia in the lower limbs. The gait was wide-based and unsteady and there was a tendency to fall to either side. The stance was unsteady and Romberg's test positive. The tendon reflexes were present and showed the slow relaxation characteristic of hypothyroidism. There was no loss of appreciation of light touch, pin prick, vibration, or passive movement. However, perception of deep and superficial pain was curiously delayed. Other modalities were perceived with a normal latency.

INVESTIGATIONS Laboratory studies showed: haemoglobin $12.4 \mathrm{~g} / 100 \mathrm{ml}$. (85\%); WBC 7,000/cu. mm with normal differential count; ESR $12 \mathrm{~mm}$ in $1 \mathrm{hr}$. (Westergren). Blood cholesterol was $223 \mathrm{mg} / 100 \mathrm{ml}$., blood urea $36 \mathrm{mg} / 100 \mathrm{ml}$. and serum sodium $143 \cdot 5$, potassium $3 \cdot 6$, chlorides $103 \mathrm{~m}$-equiv/l. Serum vitamin $B_{12}$ was 320 $\mu \mu \mathrm{g} / \mathrm{ml}$; ; serum folate level was $6.5 \mathrm{~m} \mu \mathrm{g} / \mathrm{ml}$. Thyroid studies were performed at the Middlesex Hospital, where the thyroid radioactive iodine uptake was $7 \%$ at 24 hours (normal 22 to $50 \%$ ), and $3 \%$ at 48 hours. Urinary excretion over 24 to 48 hours was $8 \%$. The 48 hour serum ${ }^{131}$ I values were: total $0.45 \%$ per 1 . (normal 0 to 0.5 ), protein-bound $0.31 \% / 1$. (normal 0 to 0.2 ). The high protein-bound level suggested a high turn-over of thyroid hormone. Tests for auto-antibodies (Dr. D. Doniach): thyroglobulin tanned cell agglutination test negative, thyroid cytoplasmic antibodies showed a low but significant titre with the immunofluorescent test, but complement fixating titre was negative. Gastric parietal cell antibodies immunofluorescent test was negative, and antinuclear factor negative. Lumbar puncture produced xanthochromic clear fluid under $185 \mathrm{~mm}$ pressure with a normal manometric response; it contained 1 lymphocyte, protein $100 \mathrm{mg} / 100 \mathrm{ml}$., WR negative, and Lange 000000 .

Otoneurological tests (Mr. W. McKenzie and Dr. J. D. Hood) showed bilateral perceptive deafness, more marked on the left, with complete loudness recruitment indicating bilateral end-organ disease.

Electro-nystagmographic studies and optokinetic tests and angular acceleration showed near normal semicircular canal function, although there was a directional preponderance to the right suggestive of some labyrinthine imbalance.

A chest radiograph showed an increased transverse cardiac diameter, but no evidence of a pericardial effusion or lung lesions. Skull radiographs were normal and those of the cervical spine showed minor spondylitic changes only. The electroencephalogram showed generalized slow wave activity at 6.5 to $8 \mathrm{~Hz}$. A few low voltage slowwave components were seen bilaterally. An electrocardiogram showed low voltage QRS complexes and flat $T$ waves in all leads, but no definite evidence of cardiac ischaemia. Electromyographic studies (Dr. R. S. Kocen) indicated a normal myogram in the right abductor pollicis $\mathrm{D}$ brevis muscle. Motor conduction velocity in the right median nerve was $57 \mathrm{~m} / \mathrm{sec}$ (normal). The sensory action of potentials obtained at the wrist in the right median nerve after stimulating the skin over the index finger had a latency of $2.9 \mathrm{msec}$ to peak with an amplitude of $12 \mu \mathrm{V}$ 虽 (normal).

COURSE AND TREATMENT In view of the clear evidence of $\stackrel{0}{\Sigma}$ hypothyroidism, thyroid replacement therapy was started on 11 February 1967 and she was initially given steroids to cover the possibility of an associated hypopituitarism. Treatment was started with triiodo-thyronine $2.5 \mu \mathrm{g} /$ day and prednisone $5 \mathrm{mg}$ six hourly. The triiodothyronine was gradually increased to $10 \mu \mathrm{g}$ /day over $10 \stackrel{\frac{\sigma}{\sigma}}{\circ}$ days, and prednisone withdrawn slowly over the same $\mathbb{Q}$ period. The patient showed an immediate response in both an increased alertness and a return of her gait towards normal. There was also an increase in the speed $\vec{\circ}$ of her tendon reflexes. However the hypertension per- $\overrightarrow{\vec{H}}$ sisted (BP 175/115 mm Hg) but without evidence of myo- $\vec{\omega}$ cardial damage on ECG records. Serial EEG records showed a gradual speeding of the background record to 8 to $9 \mathrm{~Hz}$ but some asymmetrical slow activity was seen at $7 \mathrm{~Hz}$ particularly in the right temporo-occipital area. $₫$ She was discharged home after 14 days of treatment, to continue on L-thyroxine $\mathbf{0 . 0 5} \mathrm{mg}$ daily.

She was seen at weekly intervals and, despite all-roun $\mathrm{R}$ symptomatic improvement, her hypertension becams 응 more severe. On 10 March 1967, four weeks after cond mencing treatment, her blood pressure was found to be 응 $240 / 100 \mathrm{~mm} \mathrm{Hg}$. About two hours later her speech sud 8 denly became jumbled and after 10 minutes she lost corf sciousness with apparent weakness of her right limbs. She was readmitted the same day in coma with Cheyne-Stok respiration. Her blood pressure was $220 / 120 \mathrm{~mm} \mathrm{H} \overrightarrow{\mathrm{g}} \overrightarrow{0}$ Neck stiffness was evident. Her pupils were small but equal in size. She had an apparent right facial paralysis, and no response to painful stimuli could be obtained from the right arm. There was no asymmetry in her tone or reflexes in the limbs. Lumbar puncture revealed uniformly blood stained cerebrospinal fluid under normal pressure with a xanthochromic fluid after centrifugation. The fluid contained $5,600 \mathrm{RBC} / \mathrm{c} \mathrm{mm}, 7 \mathrm{WBC} /$ c $\mathrm{mm}$, and protein $170 \mathrm{mg}$ per $100 \mathrm{ml}$. She gradually deteriorated and died after three days without regaining consciousness. L-Thyroxine $0.05 \mathrm{mg} /$ day was continued during her readmission, and the only additional therapy was reserpine given in the first 24 hours to control her hypertension. During her second admission, the EEG record was grossly abnormal, being dominated by low voltage delta and theta potentials over the whole of the left hemisphere. Alpha activity of 7 to $8 \mathrm{~Hz}$ was present over the right hemisphere.

SUMMARY The clinical picture was of a cerebellar syndrome with dominant ataxia of gait, and less ataxia of the limbs, occurring in a woman with hypothyroidism. The picture was complicated by the presence of hypertension and, four weeks after commencing thyroid hormone replacement, she apparently had a massive left sided cerebral haemorrhage and died. 
PATHOLOGICAL FINDINGS Post-mortem examination was carried out within 24 hours of death. The body was obese, the skin sallow, and the hair coarse. The heart (505 g) was enlarged from hypertrophy of the myocardium of the left ventricle. There was considerable atheroma of the aorta and large arteries; the carotid and vertebral arteries were patent. The lungs contained much oedema fluid. The changes of chronic hypertension of moderate severity were present in the kidneys, and there was a cortical adenoma (1 $\mathrm{mm}$ in diameter) in the right kidney. The thyroid (19 g) was of irregular shape; the left lobe $(5.5 \times$ $1.2 \times 1.8 \mathrm{~cm}$ thickness) was joined by an isthmus $(2.6 \mathrm{~cm}$ wide) to the right lobe $(6.0 \times 1.9 \times 0.9 \mathrm{~cm}$ thickness $)$. The cut surface was firm in consistency and pale brown in colour with thick grey bands of fibrous tissue separating the tissue into lobules; no normal colloid could be seen. The brain $(1,315 \mathrm{~g})$ and spinal cord were fixed in $10 \%$ formalin for four weeks.

On inspection the left cerebral hemisphere appeared swollen, and coronal slicing revealed a large fresh haemorrhage in the corpus striatum extending into the lateral ventricle and destroying much of the thalamus and internal capsule and reaching the medial edge of the globus pallidus. The ventricular system was displaced toward the right and there was fresh blood in the ventricles. In the right putamen and globus pallidus there was a brown slit-like zone of old haemorrhage $3.0 \mathrm{~cm}$ in length and up to $0.5 \mathrm{~cm}$ in width surrounded by a small zone of green discolouration. Anterior to the haemorrhage, and also posteriorly, the lateral ventricles were symmetrically dilated. The mid-brain was of normal appearance but the ventral portion of the pons was notably shrunken. The cerebellum was generally atrophic (Fig. 1); the mid-line structures appeared the most

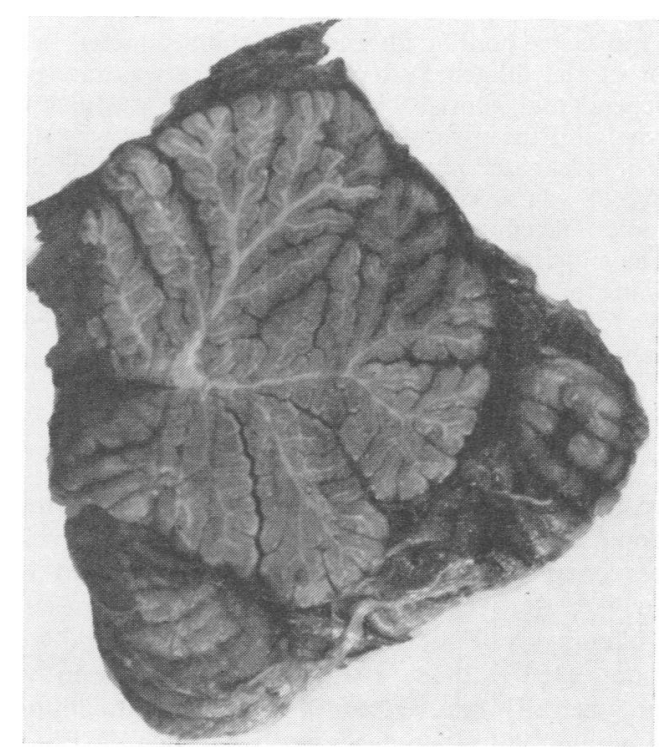

FIG. 1. Cerebellum-vermis. There is atrophy of the folia, especially in the declive. severely affected, especially the declive. The dentate nucleus appeared grey and gliotic. In the medulla the inferior olives looked small and pale. No abnormality was seen in the spinal cord.

Microscopical examination The appearances of the thyroid are typical of Hashimoto's disease (Fig. 2). Very few colloid-filled follicles remain and irregular groups of thyroid epithelial cells are surrounded by zones of lymphocytes and enclosed within a framework of dense collagenous connective tissue.

For study of the central nervous system large sections of cerebrum, cerebellum, and brain-stem together with several blocks of spinal cord were processed in celloidin.

Cerebrum In sections at levels anterior to the temporal lobes the cortex and white matter appeared normal. The leptomeninges were thickened and there was concentric medial hypertrophy of many small and moderately large meningeal arteries. At the level of the mamillary bodies the greater part of the left thalamus was destroyed by recent haemorrhage (Fig. 3) and the surrounding degenerate neural tissue was infiltrated by leucocytes. The smaller, right-sided haemorrhage in the putamen, globus pallidus, and adjoining white matter contained many histiocytes laden with altered blood pigment and the lesion was circumscribed by a thick zone of perivascular lymphocytic infiltration.

The appearances of the caudate nuclei, right thalamus, left claustrum, and putamen were normal. Much of the cortex was normal, though there was focal neuronal loss, especially in the Vth lamina of the parietal cortex. There was frequently a light subpial astrocytic gliosis. At the level of the splenium of the corpus callosum the parietal cortex was normal in appearance; one moderately large meningeal artery was stenosed by the deposition of atheroma. Posteriorly, the calcarine cortex was normal.

Cerebellum The leptomeninges were generally thickened with collagenous connective tissue often containing small aggregations of lymphocytes. Atrophy of the folia was most evident in the anterosuperior portion of the vermis. In the molecular layer the tangential and radial nerve fibres were intact, but there was a fine isomorphic gliosis in a few places. Near the pial surface and also sometimes close to the Purkinje layer there were a few large typical corpora amylacea. The Purkinje layer was frequently oedematous and the Bergmann cells were more conspicuous than normal. Loss of Purkinje cells was focal and patchy; their absence was often indicated by persisting empty basket fibres. The remaining Purkinje cells were for the most part of normal morphology but a few were shrunken and dark-staining and some were displaced into the molecular layer. Stains for axis cylinders disclosed a number of torpedo-like swellings of Purkinje axons, but not exceeding 3 or 4 in each of the folia (Fig. 4). The granule cells were less dense than usual, being apparently reduced in number. Holzer preparations revealed a light gliosis in the white matter, but no abnormalities of axons were present. In the dentate nucleus the neurones contained large amounts of lipid pigment and there was slight perivascular cuffing of neighbouring vessels. 


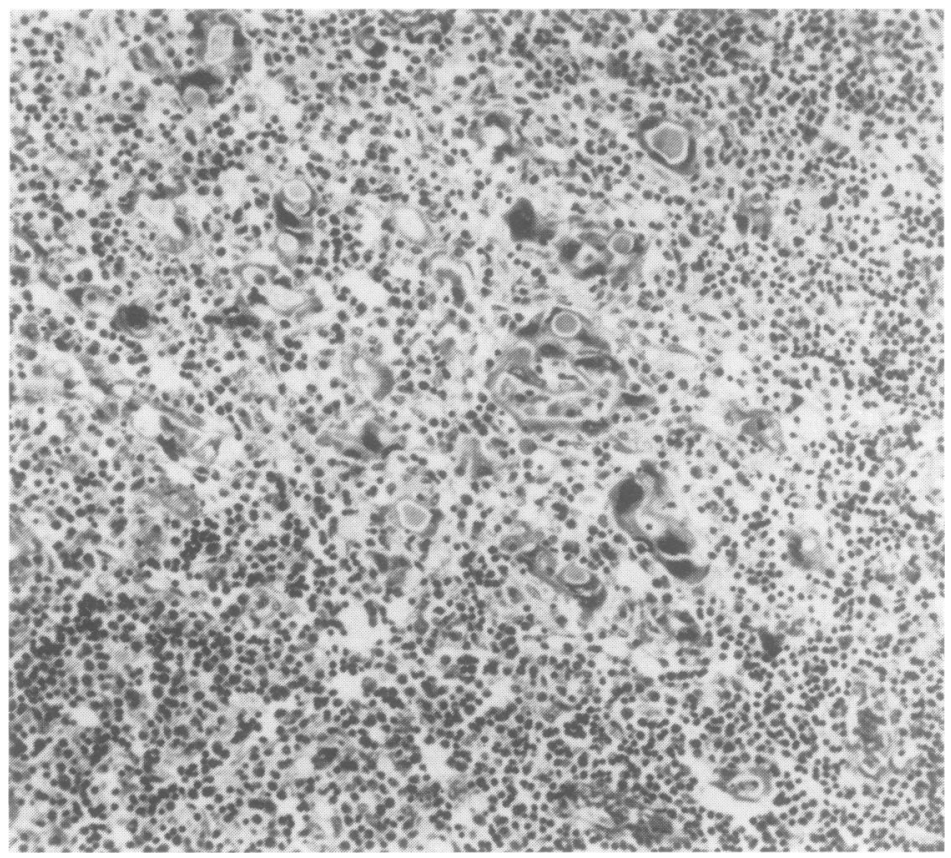

FIG. 2. Thyroid: Hashimoto's disease. Haematoxylin and eosin, $\times 125$.

Brain-stem In the mid-brain the cells of the nuclei substantiae nigrae and the peri-aqueductal grey matter were normal. The aqueduct was narrow, elongated, and contained recent blood.

In the upper pons there was atrophy of the superior and middle cerebellar peduncles, transverse pontine fibres, and to a lesser extent the descending pyramidal

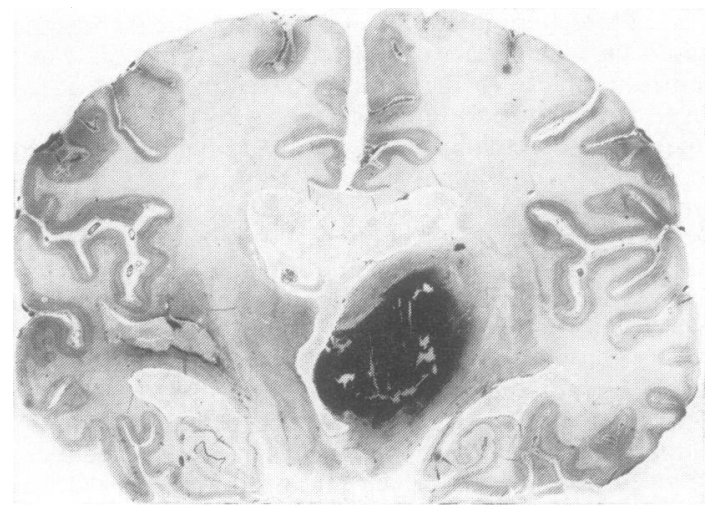

FIG. 3. Cerebrum: destruction of the left thalamus with recent haemorrhage. An older lesion is visible on the right. Nissl, $\times 0.9$. fibres. The nucleus locus caeruleus was normal. The IVt ventricle was dilated. In the mid-pons atrophy was more marked, especially of the ventral portion which wa⿳亠. clearly wasted (Fig. 5). There was notable reduction in $\vec{\theta}$ the transverse pontine fibres and in the peduncles. In the floor of the dilated IVth ventricle there was moderate subependymal gliosis. The outline of the medulla was normal and the pyramids were normal; there was slight loss of myelinated fibres at the hilum of the inferior olive, many of whose cells were distended with much lipochrome. The cuneate and gracile nuclei were normal.

There was only slight peripheral pallor of myelinstaining in the spinal cord and both anterior and posterior nerve roots were normal. Anterior horn cells were present in normal numbers.

\section{DISCUSSION}

Ataxia of gait was recognized as a feature of myxoedema in the latter part of the 19th century (references cited by Jellinek and Kelly, 1960) and was clearly related to cerebellar dysfunction in a series of papers by Söderbergh and his colleagues in Sweden $(1910,1911,1912)$. The relationship was then generally ignored until the report by Jellinek and Kelly (1960) who described six patients with disorders of equilibrium, ataxia, nystagmus, tremor, and incoordination. They emphasized the dramatic 


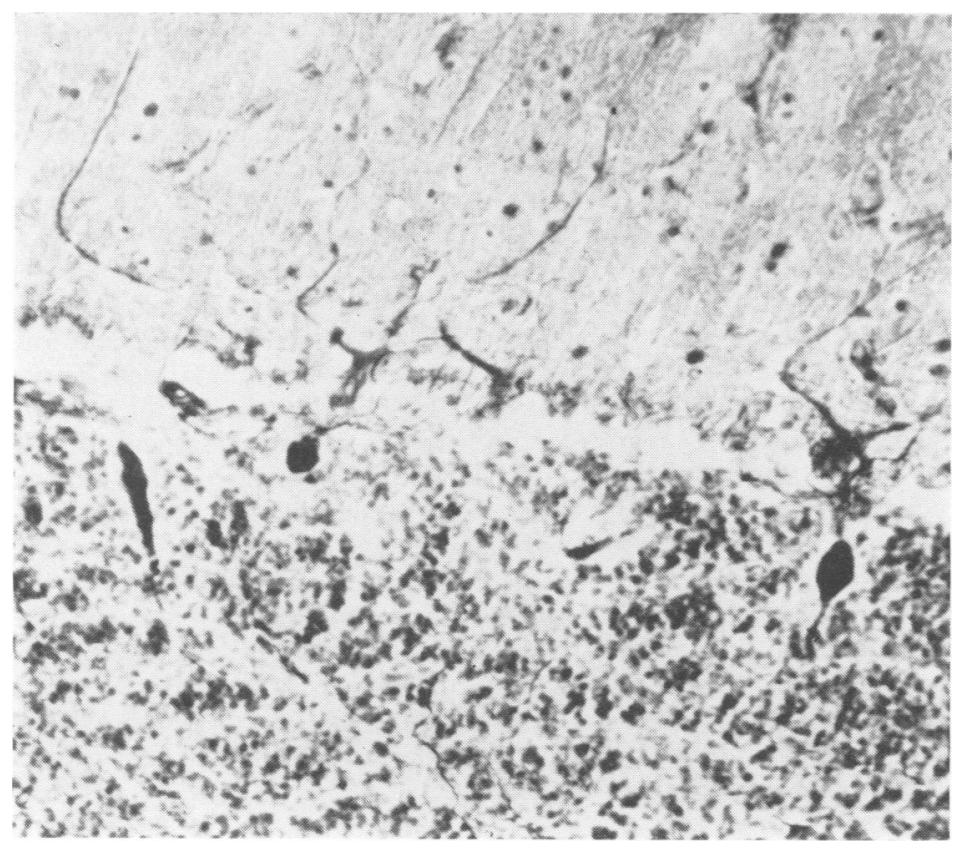

FIG. 4. Cerebellum: 'torpedoes'. Davenport's axonal stain, $\times 125$.

improvement that could be obtained when thyroid hormone was administered. In subsequent reports (Nickel and Frame, 1958; Nickel et al., 1961;

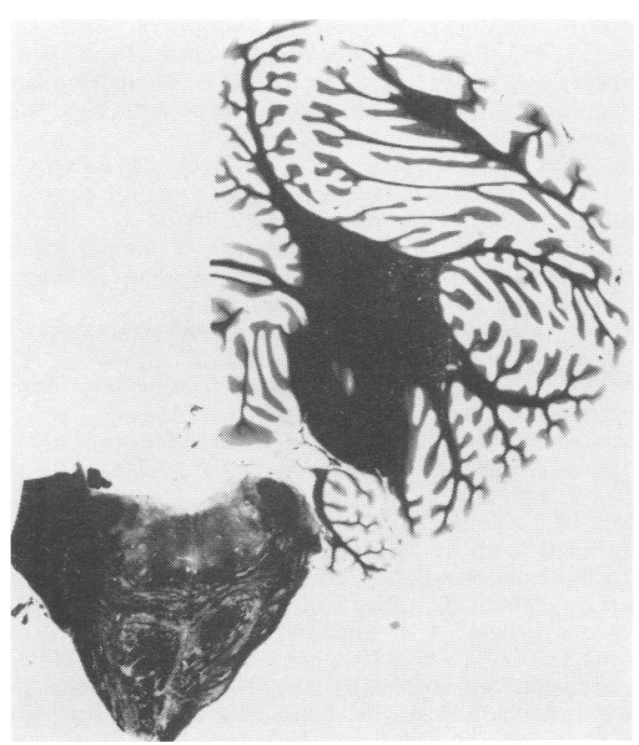

FIG. 5. Atrophy of mid-pons. Heidenhain's myelin, $\times 1$.
Cremer et al., 1969), nystagmus and incoordination have proved relatively rare, except in long-standing severe cases, and the disorder has been considered on clinical grounds to be one predominantly affecting the midline cerebellar structures. The illness suffered by the patient we have described-ataxia, mental disturbance, and deafness, with severe myxoedema-is typical. Deafness, either conductive, or more commonly perceptive (Barlow, 1922), is a common manifestation of hypothyroidism. In our patient, otoneurological tests showed bilateral perceptive deafness with complete loudness recruitment, indicating an abnormality in the end-organ rather than nerve.

It is surprising that few reports on the neuropathological changes in myxoedema have appeared particularly in view of the high mortality of myxoedema coma. Uyematsu (1920) reported the pathological findings in an elderly female with myxoedema, dementia, and ataxia, who had spent 12 years in a mental institution. Marked arteriosclerosis was found in all vessels including those of the brain and spinal cord, and among the neuropathological findings were a number of perivascular microinfarcts. However, the cerebellum showed marked degeneration of the Purkinje cells and atrophy of both the granular and molecular cell layers, and silver methods revealed swollen, degenerate axons. No correlation was made between the severity of 
these lesions and their distribution within the cerebellum. Price and Netsky (1966) described the pathological findings in a patient with long-standing myxoedema and ataxia. Unfortunately, however, there was a long history of previous alcoholism, a recognized cause of cerebellar degeneration (Victor, Adams, and Mancall, 1959), and at necropsy severe generalized atherosclerosis with multiple foci of encephalomalacia were present throughout the cerebrum. In the cerebellum there was a moderate loss of Purkinje cells and focal loss of density in the granular layer with secondary gliosis, maximal in region of the vermis. In addition, many PASpositive bodies were found throughout the brain and spinal cord including the cerebellar vermis. These resembled corpora amylacea but were described as 'atypical' in being digested by diastase and were named 'neural myxoedema bodies'. A few similar bodies were found in the cerebellum of another elderly man who died with myxoedema but without clinical evidence of ataxia. The authors suggested that these bodies were specifically related to myxoedema, although they were unable to find them in two further cases.

In the present case the pathological findings were complicated by hypertensive vascular disease and recent cerebral haemorrhages, but no question of alcoholism or nutritional deficiencies arose. The degenerative changes in the cerebellum, which were most marked in the vermis, were similar to those described by Uyematsu (1922) and Price and Netsky (1966). However, the few corpora amylacea seen presented no variation from the usual appearance. In addition, there was atrophy of the ventral portion of the pons, transverse pontine fibres, and middle and superior peduncles and these changes in the brain-stem have not been described previously in myxoedema. This raises the possibility of a coexisting recessively inherited cerebellar degeneration. We cannot exclude this possibility, but note that the changes are not typical of those reported in familial cases with a long history of ataxia.

The predominant involvement of the vermis corresponds with the clinical picture of the major dysfunction affecting equilibrium and gait. The mental changes in our patient were not accompanied by any striking pathological change in the cerebral cortex. This is in keeping with the marked clinical improvement in the four weeks of treatment up to her death.

What is the relationship between the pathological findings and the ataxia? No definite answer is possible at present, but a tentative interpretation may be made. There appear to be four important points. First, that many published cases, including the present one, have shown a prompt reversal of cerebellar symptoms with thyroid treatment. This implies a reversible metabolic factor in the genesis of ataxia, which, of course may not necessarily be reflected in structural changes. Secondly, no uniform pathological picture has emerged from the three necropsied cases of myxoedema with ataxia. Thirdly, the changes described are found in other conditions. The cerebellar cortical changes, including emphasis on degeneration in the anterior-superior vermis (but without pontine changes) have been described in alcoholic cerebellar degeneration (Victor et al., 1959) and other nutritional deficiency states (Mancall and McEntee, 1965; Victor, 1965). As already mentioned, pontine degeneration occurs in the familial ataxias. Fourthly, ataxia is a rare manifestation of myxoedema and there is no direct relationship between the severity of the two. It is thus possible that there is not a specific morbid anatomical change underlying the ataxia, and that this symptom becomes manifest when the metabolic defect of hypothyroidism is added to a pre-existing sub-clinical deficit in the cerebellar system. Further necropsy studies will show whether this is so.

\section{REFERENCES}

Barlow, R. A. (1922). The study of vestibular nerve functio in myxedema. Amer. J. med. Sci., 164, 401-414.

Cremer, G. M., Goldstein, N. P., and Paris, J. (1969 Myxedema and ataxia. Neurology (Minneap.), 19, 37-46.

Jellinek, E. H., and Kelly, R. E. (1960). Cerebellar syndrome in myxoedema. Lancet, 2, 225-227.

Mancall, E. L., and McEntee, W. J. (1965). Alterations of the cerebellar cortex in nutritional encephalopathy. Neurolog (Minneap.), 15, 303-313.

Nickel, S. N., and Frame, B. (1958). Neurologic manifesta tions of myxedema. Neurology (Minneap.), 8, 511-517.

Nickel, S. N., Frame, B., Bebin, J., Tourtellotte, W. W., Parker, J. A. , and Hughes, B. R. (1961). Myxedema neuropathy and myopathy. A clinical and pathologic study. Neurology (Minneap.), 11, 125-137.

Price, T. R., and Netsky, M. G. (1966). Myxedema and ataxia. Cerebellar alterations and 'neural' myxedema bodies. Neurology (Minneap.), 16, 957-962.

Söderbergh, G. (1910). Faut-il attributer à une perturbation des fonctions cérébelleuses certain troubles moteurs du myxoedème? Rev. neurol., 20, 487-491.

Söderbergh, G. (1911). Encore un cas de myxoedème avec symptômes cérébelleux. Rev. neurol., 22, 86-89.

Söderbergh, G. (1912). Symptômes cérébelleux dans le myxoedème. Nord. med. Ark., 45, No. 11, 1-8.

Uyematsu, S. (1920). A case of myxedematous psychosis. Clinical and pathologic report. Arch. Neurol. Psychiat. (Chic.), 3, 252-276.

Victor, M., Adams, R. D., and Mancall, E. L. (1959). A ف restricted form of cerebellar cortical degeneration occur- $\mathrm{O}$ ring in alcoholic patients. Arch. Neurol. (Chic.), 1, 579-688.

Victor, M. (1965). The effects of nutritional deficiency on the $\mathrm{O}$ nervous system. A comparison with the effects of carcinoma. In The Remote Effects of Cancer. The proceedings of a $\frac{D}{O}$ symposium sponsored by the Division of Neurology, Department of Medicine, University of Rochester School $\mathrm{N}$ of Medicine and Dentistry, 1964, pp. 134-161. Edited by $\sigma$ Lord Brain, and F. H. Norris, Jr. Grune and Stratton: N New York. 